\title{
Is Laparoscopy Really Advantageous for Splenectomy Patients?
}

\author{
Adriana Toro $^{1} \cdot$ Marco Vitale $^{2} \cdot$ Daniele Livera $^{2} \cdot$ Isidoro Di Carlo $^{2}$
}

Published online: 17 July 2017

(C) Société Internationale de Chirurgie 2017

\section{Dear Editor,}

We read with great interest the article by Wang et al. [1]. The widespread adoption of laparoscopic or robotic techniques has prompted surgeons to apply this approach to all fields of surgery. This study's interest lies in whether its results represent a definitive advance in laparoscopic surgery for diseases of the spleen.

Splenectomy is one of the more controversial surgical procedures, as for some surgeons the absence of the organ can represent a problem for patients especially with regard to overwhelming postsplenectomy infection [2], whereas other surgeons consider that life without a spleen can continue without concern [3].

In this study, the two groups of patients (submitted to open and laparoscopic surgery) underwent long operation time, prolonged in situ drainage and consequent increased length of hospital stay (LOS), and, last but not at least, the risk of major bleeding. The authors report maximum bleeding of $1000 \mathrm{~mL}$, with one patient requiring transfusion. Specifically, the need to maintain drainage for a very long time in patients undergoing laparoscopic surgery probably results from the inferior safety of partial splenectomy whereby the stump of the organ can easily bleed. Furthermore, the comparative analysis does not show any significant benefit of one approach over the other.
Autotransplantation of the spleen should be considered in all patients in whom a minimum amount of $35 \mathrm{~g}$ of spleen can be reimplanted [4], whereby the duration of surgery and hospital LOS will be shortened. Furthermore, the risk of bleeding, both intraoperatively and postoperatively, will be nullified.

\section{References}

1. Wang L, Xu J, Li F, Zhan H, Liu H, Chen W, Hu S (2017) Partial splenectomy is superior to total splenectomy for selected patients with hemangiomas or cysts. World J Surg 41:1281-1286. doi:10. 1007/s00268-016-3794-5

2. Di Carlo I, Primo S, Pulvirenti E, Toro A (2008) Should all splenectomised patients be vaccinated to avoid OPSI? Revisiting an old concept: an Italian retrospective monocentric study. Hepatogastroenterology 55:308-310

3. Scarborough JE, Ingraham AM, Liepert AE, Jung HS, O'Rourke AP, Agarwal SK (2016) Nonoperative management is as effective as immediate splenectomy for adult patients with high-grade blunt splenic injury. J Am Coll Surg 223:249-258

4. Di Carlo I, Pulvirenti E, Toro A (2012) A new technique for spleen autotransplantation. Surg Innov 19:156-161
Isidoro Di Carlo

idicarlo@unict.it

General Surgery, Patti Hospital, Patti, ME, Italy

2 Department of Surgical Sciences and Advanced Technologies "G.F. Ingrassia", Cannizzaro Hospital, University of Catania, Catania, Italy 